\title{
The Application Prospect of Cloud Computing Technology in Higher Vocational Colleges
}

\author{
Juan Zhang ${ }^{1, \text { a }}$ \\ ${ }^{1}$ Rizhao Polytechnic, Rizhao, Shandong, 276826 \\ ${ }^{\mathrm{a}}$ email
}

Keywords: Cloud Computing, Higher Vocational Colleges, Application Prospect

\begin{abstract}
Cloud computing technology is today's cutting-edge technology, but also the wisdom of the campus used in one of the core technology. Through the cloud computing technology in the wisdom of the campus application, to achieve the wisdom of the campus massive data sharing and interoperability, to provide users with cloud services. Higher vocational colleges are an important part of higher education institutions. Through the analysis of the application of cloud computing technology in the wisdom campus of vocational colleges, the proposed measures are put forward to provide technical reference for the comprehensive application of cloud computing technology in the wisdom campus And guidance.
\end{abstract}

\section{Introduction}

Cloud computing technology as a new computer technology, information technology has become one of the hot spots. Cloud computing technology is widely used to achieve remote data resources sharing, and provide cloud services. Wisdom campus is now generating more and more data resources, there are scattered data resources, difficult to focus, failed to achieve sharing and other issues, due to the lack of funding for vocational colleges and universities, the slow progress of construction and other reasons, to achieve data sharing The paper analyzes the application status and problems of the cloud computing technology in the intelligent campus of the vocational colleges, gives the relevant measures, makes the reasonable application of the cloud computing technology in the wisdom campus of the higher vocational colleges, realizes the high Intelligent Sharing and Exchange of Massive Data.

\section{The origin and definition of cloud computing}

The term cloud computing first came from Google, but the earliest cloud computing products from Amazon. Google in 2006, the official "cloud computing" the term, Amazon's cloud computing products AWS (Amazon Web Service) has been officially operated for nearly 4 years. So, some people think that Google's greatest contribution to cloud computing is for it to play a good name, and Amazon is the real pioneer of cloud computing. The meaning of cloud computing is that you can always expand, you can always get information on the calculation. The concept of "cloud" is similar to a web server here, as long as you enter the resources into the "cloud", it can take the resources you enter anytime, anywhere to deal with information, or anytime, anywhere to "cloud" enter the new Information and instructions. Its users can be a single person, it can be $\mathrm{n}$ individuals. Cloud computing technology is the application technology that can combine computer hardware, software and server. It has the characteristics and advantages of ultra-large scale, virtualization, reliability and security, and can play a huge role in dealing with data.

\section{Analysis on the Application of Cloud Computing Technology in Wisdom Campus}

After investigation, many vocational colleges in the digital campus, the wisdom of the campus construction of the lack of cloud computing technology applications related to the program content, some schools even if there is not a must-built projects, resulting in cloud computing technology in the campus information infrastructure, platform Construction and so on a series of information 
technology is ignored, and thus cause the cloud computing technology in the wisdom of vocational colleges and universities in the application of the lack of logic, before and after work out of touch and other issues.

Cloud computing technology to be fully used in the wisdom of the campus, in addition to the need to support the basic network facilities and equipment, sensing equipment, etc., but also need to have database servers, virtual servers and other cloud facilities and equipment, and must meet the technical performance requirements, to implement Running, and in the current vocational colleges, the digital campus construction is generally slow, shortage of funds, the inability to purchase equipment, resulting in the majority of schools are the lack of such facilities and equipment, individual schools and even the most basic network facilities are not guaranteed, Simply can not meet the facilities needed for cloud computing technology.

Cloud computing technology is a high-end cutting-edge technology, the use of software and hardware facilities and equipment is relatively expensive, in the wisdom of the campus application of the technology investment is relatively large, and vocational colleges themselves very nervous, the school's primary task is to ensure normal operation, So in the wisdom of the campus construction, especially cloud computing technology applications, even if there is not much; In addition, the vocational colleges on the cloud computing technical personnel team construction is not very seriously, the lack of such professionals, this is the impact An Important Factor in the Effective Application of Cloud Computing Technology.

Vocational colleges in the digital campus and intelligent campus construction planning program to rationalize the application of cloud computing technology, hardware construction, software installation, platform construction, application services and other stages to consider the cloud computing technology application infrastructure, cloud platform, Cloud services to ensure that cloud computing technology in the wisdom of the campus at all stages of building a coherent and logical, to prevent the technical program out of touch.

Cloud computing technology application infrastructure to build a scientific platform is the cloud platform, the basis of cloud services, must be as a key content to build, to save money, functional support, easy maintenance principles to carry out cloud infrastructure construction, to strengthen technical advice, Related technical problems, to prevent duplication of hardware facilities, the lack of logic, affecting the cloud platform, cloud services to achieve.

The application of cloud computing technology can realize the sharing of massive data in the intelligent campus of vocational colleges and provide personalized cloud service according to the needs of users, so as to improve the efficiency of school administrators and bring convenient service for teachers and students. School innovation and development. Therefore, the school in the information construction, we should pay attention to the wisdom of campus cloud platform technology applications, increase construction funds to ensure that the basic cloud infrastructure, cloud platform, cloud services construction funds.

Cloud computing technology is cutting-edge technology, technical complexity, professional and strong. To successfully apply cloud computing technology and build cloud technology platform services, must have professional and technical personnel to protect. Therefore, vocational colleges must pay attention to the construction of technical staff in this area, the use of company special training, the school internal training or the introduction of specialized personnel to solve the problem of shortage of technical personnel.

Cloud computing technology has a wide range of applications, the prospects are bright, but there is no fixed technology application model, vocational colleges have their own special circumstances, such as shortage of funds, lack of talent, the user is relatively less, in the wisdom of the campus construction and cloud platform Technology use process, we must consider these special circumstances to select the appropriate cloud computing application technology and cloud equipment, such as the size of the server. Vocational colleges to strengthen the actual situation of the school and cloud computing technology application research to select the appropriate cloud platform technology applied to the school's wisdom campus, to prevent non-grounding, redundant construction, function can not be guaranteed, cloud platform services can not provide such issues 
The appearance of.

Vocational colleges through the digital campus construction status and objective conditions analysis, and cloud platform technology analysis and research, in line with the actual situation of vocational colleges and universities on the wisdom of the campus cloud computing technology use architecture model for cloud computing technology in the vocational school School Wisdom Campus in the correct application of the provision of technical reference and guidance to prevent the use of cloud computing technology hybrid, technical standards do not match, features can not be achieved and other technical problems.

\section{Application of Cloud Computing Technology in Higher Vocational Colleges}

Cloud computing technology has been recognized by the majority of users, so the rapid development. In the vigorous development of higher vocational education today, the use of cloud computing technology can effectively integrate the digital resources of vocational colleges, save the cost of hardware and software, and provide a strong guarantee for the safety of teachers and students in higher vocational education. At present, the development of national information technology is accelerating, and the information construction, management and innovation of higher vocational colleges should keep pace with the development of the times. The cloud computing technology under the "cloud environment" can inject new ideas into the development of higher vocational colleges The power.

Higher vocational colleges have a large number of professional colleges and universities have more than 20 professional, and vocational courses basically include theoretical courses and practical courses, even if the same professional students in the professional direction is divided. From the teaching management point of view, the annual student placement, practice grouping and curriculum staging, teacher arrangements, etc., need to do a lot of school departments to do the work. The use of cloud computing technology can innovate the teaching management of higher vocational colleges, thus saving manpower. The use of cloud computing technology to statistics students, courses and classrooms, after the data and programming input, the computer can independently generate this semester of the curriculum and classroom schedule, both to improve efficiency and also reduce the late curriculum errors possibility.

At present, most of the institutions of the classroom has been upgraded to a multimedia classroom, even if some school funds are insufficient, but also to ensure that students in the rotation of the classroom can be used in the necessary courses to multimedia classrooms. The multimedia classroom consists of computer equipment and projection equipment. Well-equipped multimedia classrooms, but also to ensure that each student in front of a teacher can be controlled by the student machine machine. If you use cloud technology in the multimedia classroom, teachers will be able to share their resources from their own accounts or in the campus. Students can also download learning resources under the guidance of their teachers. This cloud technology can maximize the function of multimedia classrooms, but also can save teachers to search for information of the time, and different teachers of lesson preparation materials can be shared in the cloud resources, is conducive to the common help of teachers to build disciplines.

Vocational colleges and universities of the computer public courses and computer courses are required to use the engine room, the engine room management and maintenance has been an important issue in vocational colleges. Traditional computer room maintenance requires computer managers to perform hardware checks and software tests on the computer one by one, but once all the user resources and services of the computer room are available from the cloud computing center once the cloud computing technology is referenced, all of the application software Should be complete, all computer networking and connected to the cloud server, all hosts can install all the software at once. Which will greatly reduce the workload of the engine room management staff, but also save a lot of network resources. In addition, the cloud computing technology can also identify the user, each user has a successful registration of their own resources, and if there is a user on the computer operation properly, the cloud service manager will take the initiative to control the improper operation. Of course, these commands can be set in advance. At the same time, the 
introduction of cloud computing technology can make the computer run more reliable, and can minimize the probability of server error, and at very low cost to get a high computing power, to overcome the problem of server access restrictions.

The library is a common way for students to inquire about extracurricular resources. The construction of higher vocational libraries has a very important role in enhancing the overall competitiveness of higher vocational colleges. In the ordinary institutions, the library has a corresponding book query system, in general, this book query can be divided into the query within the library and through the school official website personal account password login query. In reference to cloud computing technology, the library can build a comprehensive service platform. At present, the framework of CALIS cloud service platform has been basically completed. At the same time, most universities in our country have begun to build a distributed digital library service platform. In this service platform, the library can at any time to provide users with the latest information, this process will become more rapid, thereby reducing the workload of librarians, so that the library management work to the digital direction. Students in the use of this book service platform is also more simple, only need a cloud platform connected to the terminal equipment, you can query the information on the library platform.

\section{Conclusion}

Cloud computing system with super computing and mass storage capacity, the user is particularly convenient to use. At present, cloud computing technology has been widely used in people's learning and life in vocational colleges, cloud computing technology has a broad application base, although the current use of cloud computing technology is not too much vocational colleges, but believe that with the information Technology development, cloud computing technology will be in the near future full service in the work of vocational colleges.

\section{References}

[1] Xiong Xiaofeng, You Yunjun. Application of cloud computing technology in intelligent hospital information service [J]. Science and Technology Information. 2017 (24)

[2] Yu Weimin. Large data cloud computing technology to become a tool for the fight against terrorism [J]. China Information Security. 2017 (09)

[3] Li Xiaoqing. Cloud computing technology on the impact of higher vocational education [J]. Wireless Internet Technology. 2017 (16)

[4] Shi Shouli, Liu Qian, Ai Lina. Large data cloud computing technology and its application prospect [J]. Shijiazhuang Institute of Technology Vocational College 2015 (04)

[5] Zhou Hengwei. Analysis of cloud computing technology under the large data processing system [J]. The motherland. 2017 (17)

[6] Shu Jie. Cloud computing technology in the enterprise application [J]. Private technology. 2016 (12) 